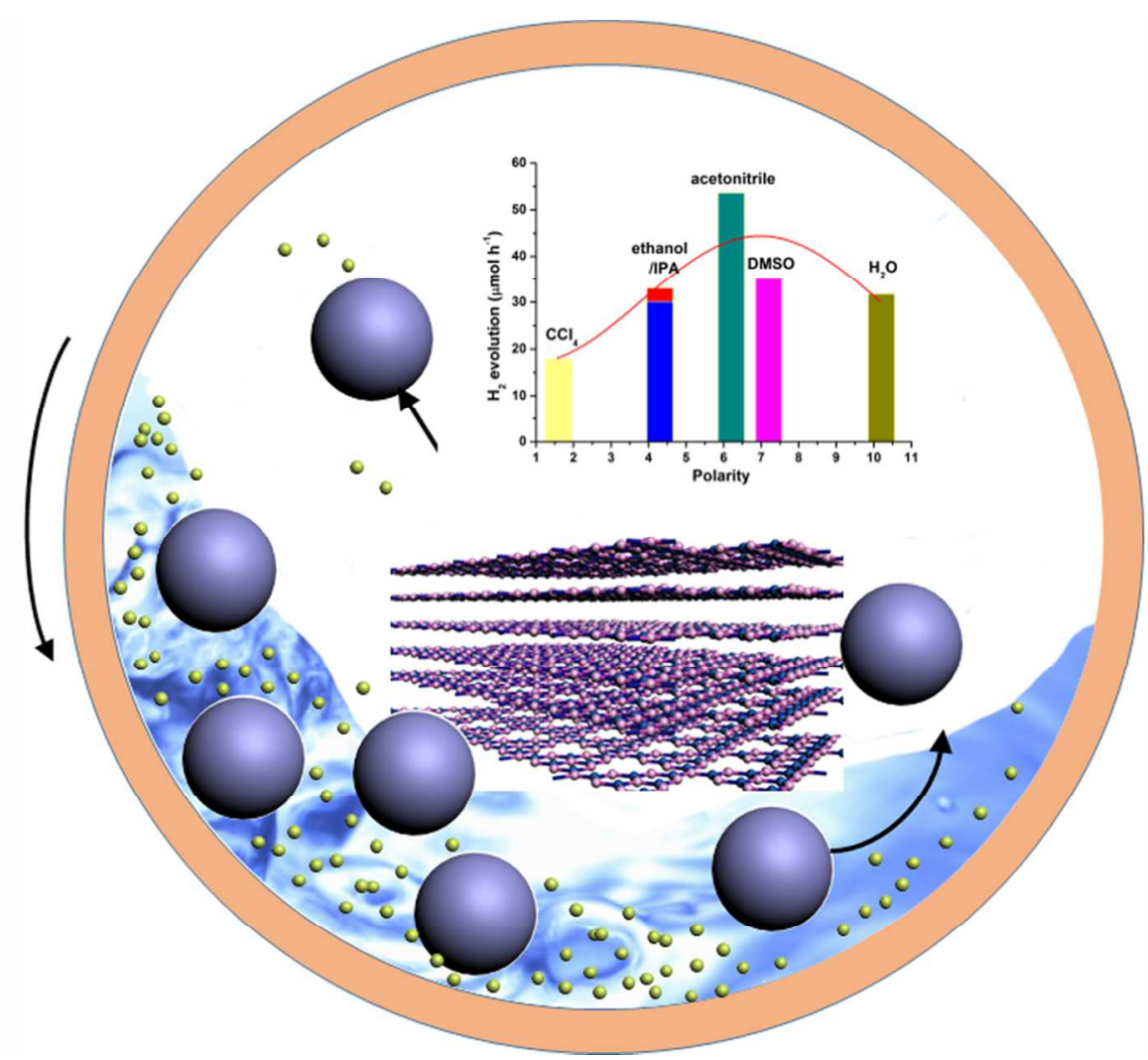

Graphitic-C3N4 with disordered structure was processed for the first time by a liquid-assisted planetary ball milling approach. 


\title{
Structure disorder of graphitic carbon nitride induced by liquid-assisted grinding for enhanced photocatalytic conversion
}

\author{
Xue Lu Wang, ${ }^{a, b}$ Wen Qi Fang, ${ }^{a, c}$ Shuang Yang, ${ }^{a}$ Pengfei Liu, ${ }^{a}$ Huijun Zhao* ${ }^{* b}$ and Hua Gui Yang* ${ }^{a, b}$ \\ Received (in $X X X, X X X)$ Xth $X X X X X X X X X 20 X X$, Accepted Xth XXXXXXXXX 20XyX \\ ${ }_{5}$ DOI: 10.1039/b000000x
}

Graphitic- $\mathrm{C}_{3} \mathrm{~N}_{4}$ with disordered structure was processed for the first time by a liquid-assisted planetary ball milling approach. Through this simple and effective mechanochemistry method, the milled samples displayed 10 outstanding visible-light photoactivity and the optimized one showed 7-fold higher $\mathrm{H}_{2}$ evolution rate than the bulk one.

Mechanochemistry, which can be trace back to the antiquity ( $4^{\text {th }}$ century BC), has seen a huge upsurge of interest in recent years and now is emerging as an excellent environmentally friendly 15 alternative to traditional solution-based approaches in a number of industries. ${ }^{1}$ Generally, mechanochemistry is defined as a "Chemical reaction that is induced by the direct absorption of mechanical energy" with methods of shearing, stretching, and grinding - typically carried out using a mortar and pestle, or a 20 ball mill within which the powder reagents are shaken violently together with stainless-steel balls in a sealed vessel. ${ }^{2}$ Subsequently, the developments have been aided by new mechanochemical techniques where the reactivity of the precursors mixture is improved by the addition of sub25 stoichiometric amounts of liquids. ${ }^{3}$ The use of liquid-assisted grinding (LAG) reveals an unexpected ability to selectively and quantitatively construct diverse materials from the same precursors.

For microscopic understanding the mechanism of the 30 traditional mechanochemical reactions, it is relevant to note the physical effects and the chemical reaction which grinding can have. Several pieces of experimental evidence have been summarized below, (a) particles diminish and expose fresh surfaces, (b) intimate mixing of reactants, introducing disordered 35 defects, amorphization, and polymorphic transformations, and (c) frictional heating, both local and bulk. ${ }^{2}$ However, in the case of a reaction involving only one reactant, the improved intimacy of contact between different reactants is not a factor. The enhanced kinetically reactions by the presence of a liquid points to a more 40 active role for the liquid, in which the liquid increases the rate of diffusion of molecules from the reactant to the product phase, and this rate enhancement increases rapidly with the decrease in reactant particle size that occurs with grinding. But for dry mechanochemical reactions, an increase in temperature can be 45 caused by frictional heating of the solid during high energy mechanical milling in a ball mill which will bring more side effect because of the high temperature. ${ }^{2,4}$

Mechanochemical method can create defects, specific to oxides, such as Schottky or Frenkel defects or crystallographic shear 50 planes (Wadsley defects). ${ }^{5}$ At the same time, organic molecular crystals are very different in some respects from metals or inorganic oxides. The crystal structure of organic solid are generally anisotropic, thus, the shapes of particles are far from being isometric and different properties can be attributed to the 55 different crystal faces. A unique feature of the organic molecular crystals mainly reflects in the co-existence between the strong covalent intramolecular bonds and several types of weaker intermolecular interactions. Mechanical treatment could selectively activate some types of bonds which remains 60 challenges by traditional methods. ${ }^{6}$ Nevertheless, as for the field of photocatalysis, the structure disorder and surface defects could provide trapping site for photoinduced carriers and hinder the recombination of electrons and holes, hence improving overall quantum efficiency. ${ }^{7}$ Thus, mechanochemical method can be 65 regarded as an available pathway to treat and synthesize photocatalyst with low cost and large scale.

Herein, we first introduced this improved mechanochemical approach, designated LAG, in construction of graphitic carbon nitride $\left(\mathrm{g}-\mathrm{C}_{3} \mathrm{~N}_{4}\right)$ with numerous bulk and surface defects. The g${ }_{70} \mathrm{C}_{3} \mathrm{~N}_{4}$ with a graphite-like structure is an efficient, simple, and sustainable photocatalytic material working with visible light, and the catalytic activity of which is closely related to its defects and termination sites of the sheet. ${ }^{8}$ Thus, defects and structure disorder may be significant influence factors on its photocatalytic 75 performance, as well as electronic structure, charge transport and surface properties. It is well known that LAG with different solvents may have different effects, which is significantly influenced by the surface tensions of them. ${ }^{2}$ The adhesion between the $\mathrm{g}-\mathrm{C}_{3} \mathrm{~N}_{4}$ and the liquid along with the impact force 80 lead to some advantageous structure and surface defects with the

Table 1 Physicochemical properties of $\mathrm{CN}$ and LAG-CN-x samples.

\begin{tabular}{cccccc}
\hline Catalyst & Solvent & Polarity & $\begin{array}{c}\mathrm{C} / \mathrm{N} \\
\text { atmomic }\end{array}$ & $\begin{array}{c}\mathrm{S}_{\mathrm{BET}}{ }^{[\mathrm{a}]} \\
{\left[\mathrm{m}^{2} \mathrm{~g}^{-1}\right]}\end{array}$ & $\begin{array}{c}\mathrm{HER}^{[\mathrm{b}]} \\
{\left[\mu \mathrm{mol} \mathrm{h}^{-1}\right]}\end{array}$ \\
\hline $\mathrm{CN}$ & $/$ & $/$ & 0.675 & 5.1 & 8.53 \\
LAG-CN-1 & $\mathrm{H}_{2} \mathrm{O}$ & 10.2 & 0.680 & 23.7 & 31.76 \\
LAG-CN-2 & $\mathrm{CCl}_{4}$ & 1.6 & 0.686 & 15.9 & 17.84 \\
LAG-CN-3 & ethanol & 4.3 & 0.678 & 23.9 & 33.05 \\
LAG-CN-4 & IPA & 4.3 & 0.678 & 22.7 & 30.14 \\
LAG-CN-5 & acetonitrile & 6.2 & 0.678 & 21.6 & 53.61 \\
LAG-CN-6 & DMSO & 7.2 & 0.680 & 9.6 & 35.14 \\
\hline
\end{tabular}

[a] The surface area; [b] $\mathrm{H}_{2}$ evolution rate $(30 \mathrm{mg})$. 
cooperation of the shearing, stretching and grinding.

The LAG samples were synthesized by ball milling $\mathrm{g}-\mathrm{C}_{3} \mathrm{~N}_{4}$ in the presence of different organic solvents (see details in Supplementary Information Section 1). Through this simple and ${ }_{5}$ effective mechanochemistry approach, bulk $\mathrm{g}-\mathrm{C}_{3} \mathrm{~N}_{4}$ might be transformed into some smaller, compressed, or squeezing pieces with some vacancy or other disordered activation defects, and all obtained samples show good dispersion in the water. For simplicity, the resulting LAG samples were denoted as LAG-CN$10 \mathrm{x}$, where $\mathrm{x}$ is an arbitrary number that represents the organic solvents with different polarities (see Table 1). The polarities we chose here are spanning from 1.6 to 10.2. Among all the solvent, acetonitrile seem to be a more promising candidate with appropriate surface tension $\left(\sim 29 \mathrm{~N} \mathrm{~m}^{-1}\right) .{ }^{9}$ Considering the 15 complexity of the solvent itself, we will focus on analysing and comparing the typical samples of CN, LAG-CN-1, and LAG-CN5.
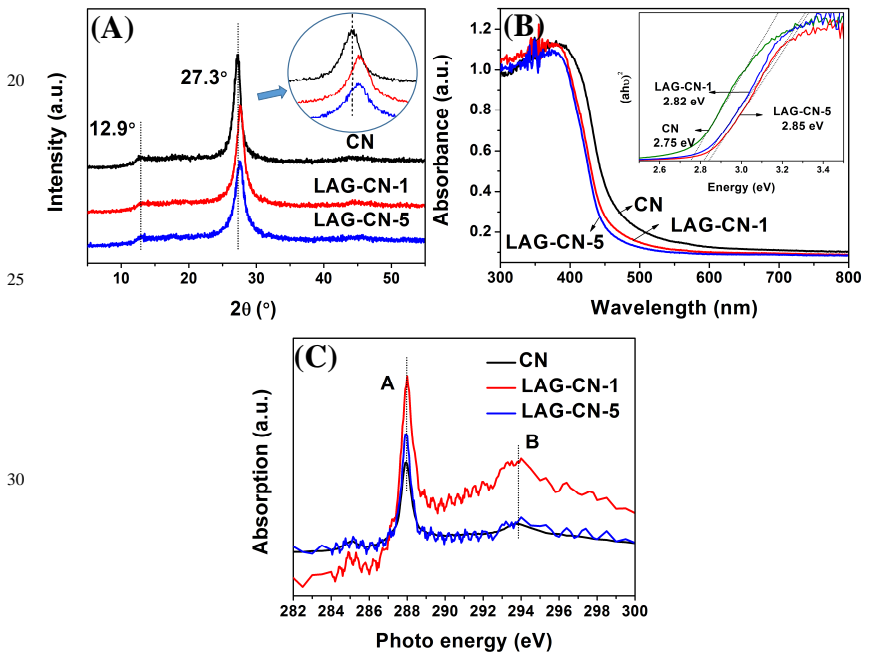

35

Fig. 1 XRD patterns (A), UV-vis absorption spectra (B), the bandgap determination (B, inset), and the $\mathrm{C}$ K-edge XANES spectra $(\mathrm{C})$ of $\mathrm{CN}$, LAG-CN-1 and LAG-CN-5 samples.

40 The texture and chemical structure of the samples were characterized with various physical and chemical techniques. Carbon and nitrogen stoichiometry of the samples was determined by elemental analysis (Table 1). It should be noted that, according to the EL results, the atomic $\mathrm{C} / \mathrm{N}$ molar ratios of ${ }_{45} \mathrm{LAG}-\mathrm{CN}-\mathrm{x}$ samples are higher than $\mathrm{CN}$, but lower than that of the theoretical value of the ideal crystal $g-\mathrm{C}_{3} \mathrm{~N}_{4}$. Taking LAG$\mathrm{CN}-5$ for example, the bulk atomic $\mathrm{C} / \mathrm{N}$ ratio has increased from pristine 0.675 to 0.678 for the LAG-CN-5. However, the surface atomic ratio of $\mathrm{C}$ to $\mathrm{N}$ increases from 0.80 to 0.90 according to 50 the percentages of $\mathrm{C}$ and $\mathrm{N}$ determined by XPS. Obviously, the surface of LAG-CN-5 is poorer in nitrogen than $\mathrm{CN}$, indicating that mechanical milling may result in the surface defects (nitrogen loss) with the assistance of the organic solvent and led to the increase in the BET surface area. ${ }^{10}$ However, there are not 55 a positive correlation between the increased BET surface area and the hydrogen production. Accordingly, the activation defects play a significant role in the whole process.

Fig. 1A shows the XRD patterns of CN, LAG-CN-1 and LAG-
CN-5 samples. A highly resembled structure can be determined, 60 with the arising of reflection peaks (002) and (100) at $\sim 27.3^{\circ}$ and $\sim 12.9^{\circ}$, respectively. The dominate characteristic interlayer stacking peak of the $\pi$-conjugated aromatic system of LAG-CN-x, indexed for graphitic like materials as the (002) peak, slightly upshift; that is, the average interlayer distance of the LAG-CN-x is 65 notably compressed to a smaller d-spacing value, according to Bragg`s law. The reaction upon LAG presumably could influence the conformation and the connectivity of the resultant sheets, ascribed to the shear stress and the impact-induced local heating and high local pressures. This can proved that there existed some 70 structure disorder and surface defects after LAG. The tendency offers an important tool to tune the physical and chemical properties of the samples, and hence to adjust their photocatalytic performance. . $^{8,11}$

As estimated from the UV-vis spectrum (Fig. 1B and Fig. S1), 75 the optical absorption edges of LAG-CN-x presents blue shifts compared with that of $\mathrm{CN}$, corresponding to an increase in band gap from $2.75 \mathrm{eV}$ of $\mathrm{CN}$ to $2.85 \mathrm{eV}$ of LAG-CN-5. Generally, the blue shifts can be attributed to the decreased conjugation length or quantum confinement effects of the samples. Moreover, the 80 hypsochromic-shift performance of LAG-CN-x is presumably due to the strong quantum confinement effects, because of the enhanced surface area. ${ }^{11}$ Moreover, the hypsochromic-shift performance of LAG-CN-x in the spectrum can be due to an $\mathrm{H}$ aggregates type intermolecular packing between the layers. ${ }^{12}$

85 Looking at the $\mathrm{C}$ K-edge XANES spectra in Fig. 1C, the samples all exhibit two distinct peak at round 288 (A) and $294 \mathrm{eV}$ (B). The signal $\mathrm{A}$ is attributed to the sp2-bonded carbon in $\mathrm{N}$ containing aromatic rings $(\mathrm{N}-\mathrm{C}=\mathrm{N})$ which is regarded as the major carbon species in the $\mathrm{g}-\mathrm{C}_{3} \mathrm{~N}_{4}$ polymer. The intensity of it ${ }_{90}$ for the LAG-CN-x sample is found to be higher than that of bulk $\mathrm{CN}$, indicating the compressed average interlayer distance and the disordered structure. On the other hand, the feature B is related to interlayer states or transitions to $\mathrm{sp} 3$ hybridized states due to hydrogenation or oxygenated groups. ${ }^{13}$ Additionally, the 95 TEM images of CN, LAG-CN-1 and LAG-CN-5 are shown in Fig. 2. They all display the typical layered silk structure and similar to the results of the nitrogen adsorption-desorption experiments.

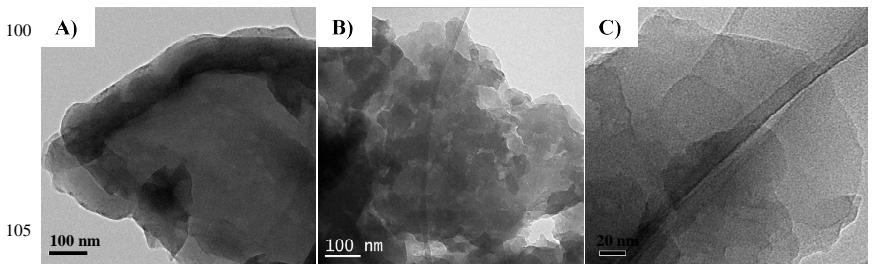

Fig. 2 TEM images of CN, LAG-CN-1 and LAG-CN-5 samples.

110 Typical FTIR spectra of the samples are displayed in Fig. 3. All of the characteristic vibration modes show that the spectra of the three samples are highly similar. The set of peaks between 1200 and $1700 \mathrm{~cm}^{-1}$ is assignable to the feature-distinctive stretch modes of tri-s-triazine heterocyclic ring $\left(\mathrm{C}_{6} \mathrm{~N}_{7}\right)$ unites, while the 115 sharp peak at $\sim 807 \mathrm{~cm}^{-1}$ is ascribed to their breathing mode. The broad bands in the range of the $3000-3700 \mathrm{~cm}^{-1}$ region can be 
interpreted as the residual $\mathrm{N}-\mathrm{H}$ components and the O-H bands, suggesting the partial hydrogenation of some nitrogen atoms and the surface-absorbed $\mathrm{H}_{2} \mathrm{O}$ molecules, respectively. In comparison with $\mathrm{CN}$, the vibrations of LAG-CN-1 and LAG-CN-5 become 5 slightly stronger. Generally, the enhanced absorption peak around the region is presumably assigned to the absorbed $\mathrm{H}_{2} \mathrm{O}$ and the weak uncondensed amine groups. However, there is no $\mathrm{H}_{2} \mathrm{O}$ in the grinding environment of LAG-CN-5, thus, we attribute the enhancement to the distorted incomplete structure (disordered 10 defects). Notably, the whole adsorption peak of LAG-CN-5 becomes a partly blue-shift compared with the $\mathrm{CN}$. As we all know, the hypsochromic-shift is largely induced by the inductive effect, which may change the size, shape and density distribution of its electron cloud, and the spatial effects. Therefore, the shift 15 would be regard as the generation of surface defects and the distorted structure caused by LAG. Moreover, the absence of $\mathrm{CN}$ bonds near $2200 \mathrm{~cm}^{-1}$ excludes the possibility of self trimerzation of the $-\mathrm{CN}$ group in acetonitrile. This strongly indicates that acetonitrile only acts as a subcritical solvent to 20 mediate the grinding, but involved in the chemical reaction. ${ }^{14}$

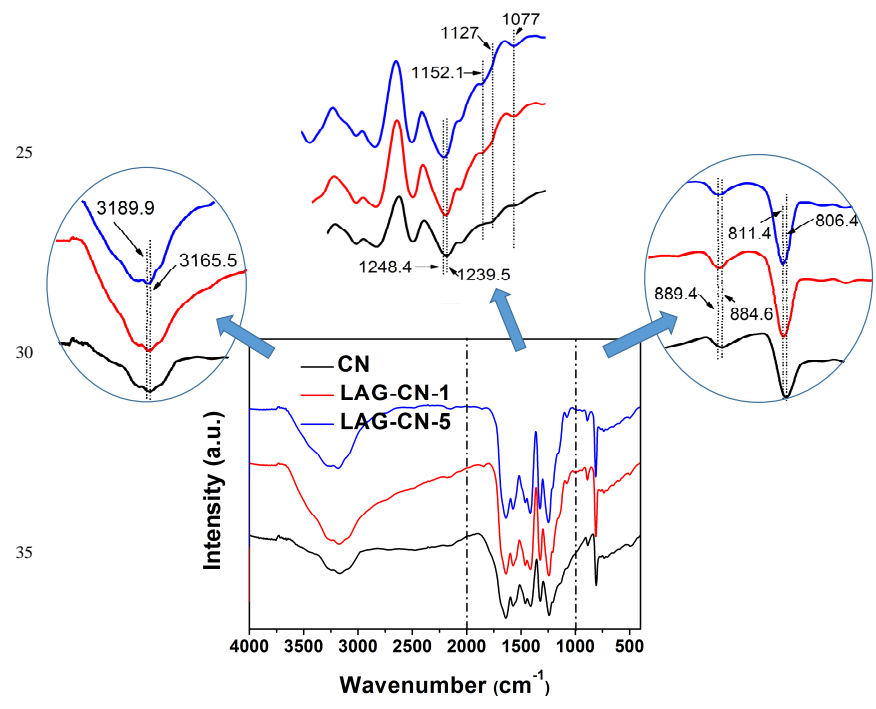

40

Fig. 3 FTIR spectra of CN, LAG-CN-1 and LAG-CN-5 samples.

In the XPS survey spectrum (Fig. S2A), all show three elements ( $\mathrm{C}, \mathrm{N}$ and $\mathrm{O}$ ). This gives evidence that the LAG 45 samples remain the same framework with the $\mathrm{CN}$. A similar tendency is observed for the C1s signals (Fig. S2B), which were deconvoluted into three peaks at binding energies of $284.8 \mathrm{eV}$, $288.3 \mathrm{eV}$ and $289.4 \mathrm{eV}$, which can be ascribed to the sp2 C-C bonds, $\mathrm{N}=\mathrm{C}-\mathrm{N}$ coordination and the $\mathrm{C}-\mathrm{O}$ groups induced by 50 unavoidable oxidation of the samples, repectively. The N1s spectra in Fig. S2C show three peaks centering at 398.7, 399.8 and $401.1 \mathrm{eV}$. The dominance of the main peak (398.7 eV) originating from the sp2-hybridized nitrogen involved in triazine rings $(\mathrm{C}-\mathrm{N}=\mathrm{C})$. The two peaks at about 399.8 and $401.1 \mathrm{eV}$ can 55 be ascribed to tertiary nitrogen $\left(\mathrm{N}-(\mathrm{C})_{3}\right)$ and amino functional groups having a hydrogen atom $(\mathrm{C}-\mathrm{N}-\mathrm{H})$, respectively. The presence of the $\mathrm{C}-\mathrm{N}-\mathrm{H}$ groups originates from the incomplete condensation of the poly(tri-s-triazine) structures. ${ }^{8,15}$
The larger bandgaps by $0.07 \mathrm{eV}$ and $0.1 \mathrm{eV}$ of the LAG-CN-1 60 and LAG-CN-5 compared to $\mathrm{CN}$ are further confirmed by the blue shift of the fluorescence emission by $8 \mathrm{~nm}$ and $13 \mathrm{~nm}$, respectively (Fig. S3). This might be attributed to the quantum confinement effect by shifting the conduction and valence band edges in opposite directions. ${ }^{10}$

65
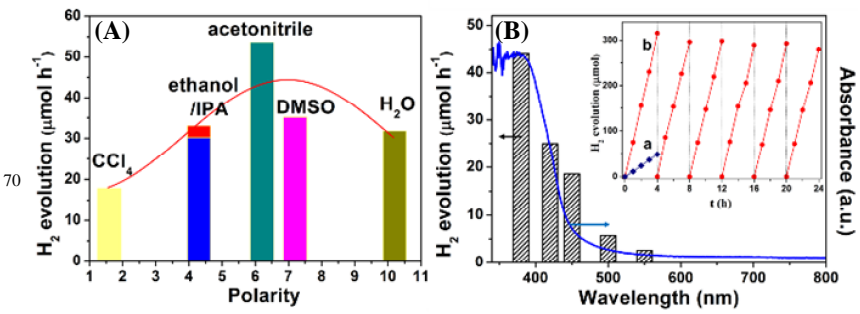

Fig. 4 (A) The rate of $\mathrm{H}_{2}$ evolution on LAG-CN-x samples prepared with 75 different polarity organic solvent LAG under visible-light irradiation $(\lambda>$ $420 \mathrm{~nm}$ ). (B) Steady rate of $\mathrm{H}_{2}$ production in aqueous triethanolamine solution (10 vol\%) by $50 \mathrm{mg} 3.0 \mathrm{wt} \%$ Pt-deposited LAG-CN-5 samples as a function of wave-length of the incident light. Ultraviolet-visible absorption spectrum of the catalyst is also shown for comparison. Inset is 80 the stability test of (b) 3.0 wt\% Pt-deposited LAG-CN-5 for $\mathrm{H}_{2}$ production under visible light, the (a) $\mathrm{CN}$ samples is also shown for comparison.

The photocatalytic performance of the as-prepared samples 85 were evaluated by $\mathrm{H}_{2}$ evolution under visible light irradiation (Fig. 4A). Notably, all samples show an enhanced $\mathrm{H}_{2}$ evolution rate (HER) over $\mathrm{CN}$ to varying extents, and LAG-CN-5, with a $4.9 \%$ apparent quantum efficiency at $420 \mathrm{~nm}$, shows the highest activity for its suitable polarity of acetonitrile solvent. 90 Simultaneously, in order to confirm the inference, we also chose two solvents with the similar polarity (4.3). As expected, the two samples exhibit the close HER. Thus, polarity is of course one of the important influence factors that affect the mechanochemical process as well as the final products in LAG. However, more 95 details investigations are still needed for real quantitative statements.

The durability of the LAG-CN-5 sample was evaluated in a water/triethanolamine solution (see the details in Section S1) by a $24 \mathrm{~h}$ experiment with intermittent evacuation every $4 \mathrm{~h}$ under 100 visible light $(>420 \mathrm{~nm})$. As presented in Fig. 4B (inset), the $\mathrm{H}_{2}$ produced increases steadily without noticeable deterioration of the activity. The turnover number with respect to the melem units and $\mathrm{Pt}$ atoms are 3.19 and 115.3, respectively, clearly indicating that the reaction indeed proceeds catalytically. Additionally, 105 wavelength dependence of the photocatalytic $\mathrm{H}_{2}$ evolution was performed on LAG-CN-5, and different monochrome filters were used. As depicted in Fig. 4B, the $\mathrm{H}_{2}$ evolution rates match well with the diffuse reflectance spectra. The active wavelength is actually prolonged to wavelengths as long as $550 \mathrm{~nm}$.

110 In summary, structure disordered $\mathrm{g}-\mathrm{C}_{3} \mathrm{~N}_{4}$ samples were successfully synthesized by a facile LAG approach. The cooperative effect of shearing, stretching and grinding reforms the structure and surface of $\mathrm{g}-\mathrm{C}_{3} \mathrm{~N}_{4}$. The resulting LAG-CN samples, therefore, harbour widen the bandgap, selectively 115 activation of some defect points, and lead to a very good photoctalytic activity for hydrogen evolution under visible light. 
Although mechanochemistry has historically been a sideline approach to synthesis, but its practicality, advantage and effectivity all can move it into the mainstream within the realm of chemical research.

\section{${ }_{5}$ Acknowledgements}

We thank Prof. Caihao Hong for the valuable discussion on XANES. This work was financially supported by National Natural Science Foundation of China (21373083, 21203061), SRF for ROCS, SEM, SRFDP, Programme for Professor of ${ }_{10}$ Special Appointment (Eastern Scholar) at Shanghai Institutions of Higher Learning, Shanghai Municipal Natural Science Foundation (12ZR1407500), Fundamental Research Funds for the Central Universities (WD1313009 , WM1314018 , WD1214036), and China Postdoctoral Science Foundation 15 (2012M511056, 2013T60425).

\section{Notes and references}

${ }^{a}$ Key Laboratory for Ultrafine Material of Ministry of Education, School of Materials Science and Engineering, East China University of Science and Technology, Shanghai, 200237, China. Fax: +86-21-64252127; Tel: 20 +86-21-64252127; E-mail: hgyang@ecust.edu.cn

${ }^{b}$ Centre for Clean Environment and Energy, Gold Coast Campus, Griffith University, Queensland, 4222, Australia.E-mail: h.zhao@griffith.edu.au ${ }^{c}$ QLD Micro- and Nanotechnology Centre, Griffith University, Nathan Campus, QLD 4111, Australia

$25 \dagger$ Electronic Supplementary Information (ESI) available: Experimental details, UV-vis adsorption spectra, XPS spectra, fluorescence emission spectra and TEM images. See DOI: 10.1039/b000000x/

1 (a) L. Takacs, J. Mineral Met. Mater. Soc., 2000, 52, 12; (b) K. D. M. 30 Harris, Nat. Chem., 2013, 5, 12-14.

2 (a) S. L. James, C. J. Adams, C. Bolm, D. Braga, P. Collier, T. Friscic, F. Grepioni, K. D. M. Harris, G. Hyett, W. Jones, A. Krebs, J. Mack, L. Maini, A. G. Orpen, I. P. Parkin, W. C. Shearouse, J. W. Steed and D. C. Waddell, Chem. Soc. Rev., 2012, 41, 413-447; (b) G.

35 A. Bowmaker, Chem. Commun., 2013, 49, 334-348.

3 T. Friscic, I. Halasz, P. J. Beldon, A. M. Belenguer, F. Adams, S. A. J. Kimber, V. Honkimaki and R. E. Dinnebier, Nat. Chem., 2013, 5, 66-73.

4 L. Takacs, Prog. Mater. Sci., 2002, 47, 355-414.

405 (a) V. Sepelak, I. Bergmann, S. Kipp and K. D. Becker, Z. Anorg. Allg. Chem., 2005, 631, 993; (b) V. Sepelak, A. Düvel, M. Wilkening, K. Becker and P. Heitjans, Chem. Soc. Rev., 2013, 42, 7507-7520.

6 (a) E. Boldyreva, Chem. Soc. Rev., 2013, 42, 7719; (b) C. F. Burmeister, A. Kwada, Chem. Soc. Rev., 2013, 42, 7660.

${ }_{45} 7$ X. B. Chen, L. Liu, P. Y. Yu and S. S. Mao, Science, 2011, 331, 746.

8 (a) X. Wang, K. Maeda, A. Thomas, K. Takanabe, G. Xin, J. M. Carlsson, K. Domen and M. Antonietti, Nat. Mater., 2009, 8, 76-80; (b) A. Thomas, A. Fischer, F. Goettmann, M. Antonietti, J. Müller, R. Schlöql and J. M. Carlsson, J. Mater. Chem., 2008, 18, 4893-4908.

509 G. Korosl and E. Kovats, J. Chem. Eng. Data, 1981, 26, 323-332.

10 P. Niu, L. Zhang, G. Liu, H. Cheng, Adv. Funct. Mater., 2012, 22, 4763-4770.

11 Y. Cui, J. Zhang, G. Zhang, J. Huang, P. Liu, M. Antonietti and X. Wang, J. Mater. Chem., 2011, 21, 13032-13039.

5512 (a) X. H. Li, J. Zhang, X. Chen, A. Fischer, A. Thomas, M. Antonietti, Chem. Mater., 2011, 23, 4344-4348; (b) Y. Cui, J. Zhang, G. Zhang, J. Huang, M. Antonietti, J. Mater. Chem., 2011, 21, 1303213039.

13 (a) L. Liu, T. K. Sham, W. Han, Phys. Chem. Chem. Phys., 2013, 15, 60 6929-6934; (b) N. Hellgren, J. Guo, Y. Luo, C. Såthe, A. Agui, S. Kashtanov, J. Nordgren, H. Ågren, J. E. Sundgren, Thin Solid Film, 2005, 471, 19-34.

14 Y. Cui, Z. Ding, X. Fu and X. Wang, Angew. Int. Ed. Chem., 2012, 51, 11814-11818.
6515 G. Zhang, J. Zhang, M. Zhang and X. Wang, J. Mater. Chem., 2012, 22, 8083-8091. 

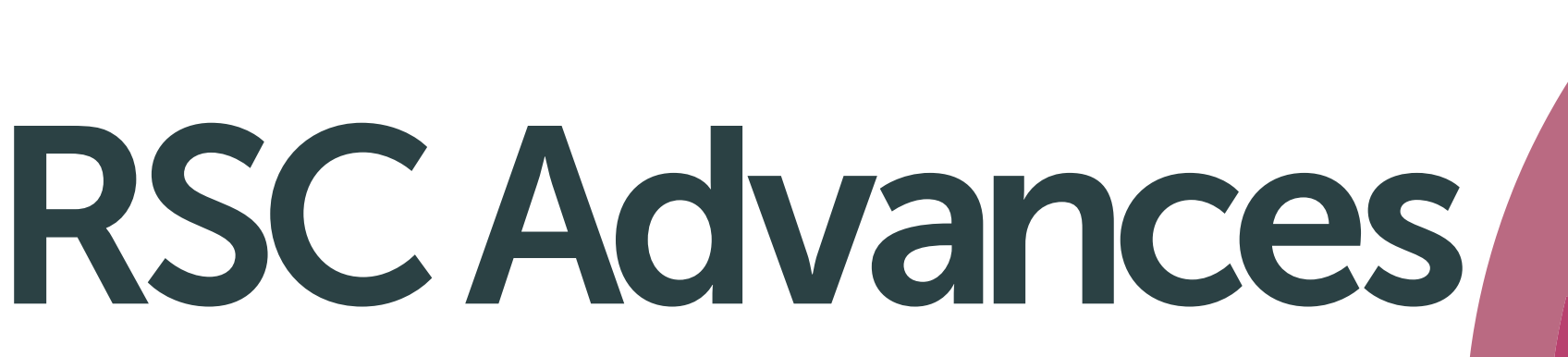

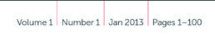

\section{RSC Advances}

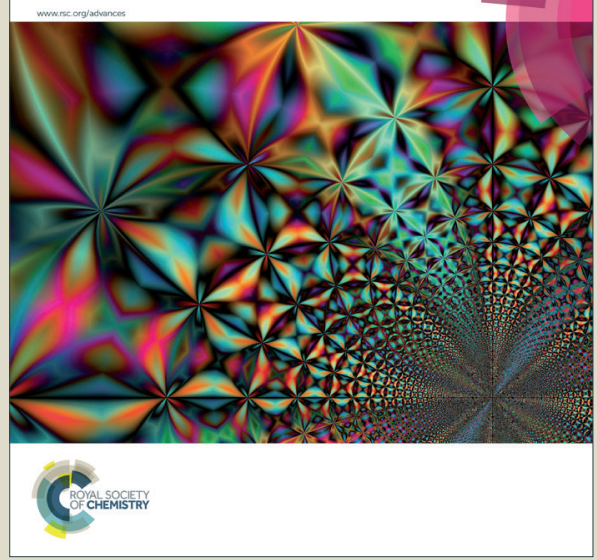

This is an Accepted Manuscript, which has been through the Royal Society of Chemistry peer review process and has been accepted for publication.

Accepted Manuscripts are published online shortly after acceptance, before technical editing, formatting and proof reading. Using this free service, authors can make their results available to the community, in citable form, before we publish the edited article. This Accepted Manuscript will be replaced by the edited, formatted and paginated article as soon as this is available.

You can find more information about Accepted Manuscripts in the Information for Authors.

Please note that technical editing may introduce minor changes to the text and/or graphics, which may alter content. The journal's standard Terms \& Conditions and the Ethical guidelines still apply. In no event shall the Royal Society of Chemistry be held responsible for any errors or omissions in this Accepted Manuscript or any consequences arising from the use of any information it contains. 